\title{
ORIGINAL ARTICLE Persistent effects of women's parity and breastfeeding patterns on their body mass index: results from the Million Women Study
}

\author{
KL Bobrow ${ }^{1}$, MA Quigley ${ }^{2}$, J Green ${ }^{1}$, GK Reeves ${ }^{1}$ and V Beral ${ }^{1}$ for the Million Women Study Collaborators ${ }^{3}$
}

OBJECTIVE: To explore the long-term effects of women's childbearing patterns on their body mass index. DESIGN: Cross-sectional analysis.

SETTING: Population-based study of UK women.

PARTICIPANTS: 740628 postmenopausal participants in the Million Women Study who reported their height, weight, reproductive histories and other relevant factors.

MAIN OUTCOME MEASURES: Standardized mean BMI $\left(\mathrm{kg} \mathrm{m}^{-2}\right)$ in groups defined by their parity and breastfeeding history. RESULTS: Women were aged 57.5 (s.d. 4) years on average, and had a mean BMI of $26.2 \mathrm{~kg} \mathrm{~m}^{-2}$ (s.d. 5); $88 \%$ were parous, with 2.1 (s.d. 1.2) children on average. The standardised mean BMI increased progressively with the number of births from $25.6 \mathrm{~kg} \mathrm{~m}^{-2}$ (95\% confidence interval $(\mathrm{Cl}): 25.5-25.6)$ in nulliparous women up to $27.2 \mathrm{~kg} \mathrm{~m}^{-2}$ (Cl: $\left.27.2-27.3\right)$ for women with four or more births, a difference of $1.7 \mathrm{~kg} \mathrm{~m}^{-2}$ (Cl: 1.6-1.7). Among the parous women $70 \%$ had ever breastfed and their average total duration of breastfeeding was 7.7 (s.d. 8.8) months. At every parity level the standardised mean BMI was significantly lower among women who had breastfed than those who had not, decreasing by $0.22 \mathrm{~kg} \mathrm{~m}^{-2}(\mathrm{Cl}: 0.21-0.22)$ for every 6 months of breastfeeding, that is, women's mean BMI was $1 \%$ lower for every 6 months that they had breastfed. These associations were highly statistically significant $(P<0.0001)$ and independent of the effects of socioeconomic group, region of residence, smoking and physical activity.

CONCLUSIONS: Childbearing patterns have a persistent effect on adiposity in this population. The reduction in BMI associated with just 6 months breastfeeding in UK women could importantly reduce their risk of obesity-related disease as they age.

International Journal of Obesity (2013) 37, 712-717; doi:10.1038/ijo.2012.76; published online 10 July 2012

Keywords: childbearing; parity; breastfeeding; body mass index; adiposity; long-term

\section{INTRODUCTION}

Even a modest $1 \%$ reduction in body mass index (BMI) in western countries would substantially reduce the number of obesityrelated diseases and their costs. ${ }^{1}$ Excess body weight is an important risk factor for vascular disease and, to a lesser extent, for cancer. $^{2,3}$ In a prospective study of almost one million people from high-income countries, a $1 \%$ increase in average BMI was associated with about a $1 \%$ increase in all-cause mortality. ${ }^{2}$

Among reproductive-aged women in developed countries weight tends to increase after each birth but the short-term effect of breastfeeding on weight is less clear, ${ }^{4-8}$ though breastfeeding has been associated with a lower risk of the metabolic syndrome and of other conditions associated with adiposity. ${ }^{9,10}$ In the longer term, after a woman's reproductive years are over, some investigators have also found that various measures of adiposity are increased the more children women had, although the evidence is somewhat inconsistent. ${ }^{11-16}$ To our knowledge only two small studies have looked at the association between breastfeeding history and postmenopausal adiposity and their findings suggest a possible reduction in BMI associated with breastfeeding. ${ }^{17,18}$ Women's BMl is known to be related to socioeconomic factors, smoking and physical activity, and these factors are associated with reproductive history. ${ }^{19-22}$ We report here on the association between women's childbearing and breastfeeding history, and their BMI in later life in a large population of postmenopausal women, taking into account the effects of potential confounding factors.

\section{MATERIALS AND METHODS}

Data collection and definitions

The Million Women Study is a prospective study of women aged between 50 and 64 years when they were invited for screening by the National Health Service (NHS) Breast Screening Programme in England and Scotland between 1996 and $2001 .{ }^{23}$ Women completed a study questionnaire at recruitment which asked about height, weight, reproductive history, socioeconomic and lifestyle factors, and other personal characteristics. Questions on breastfeeding were added to the baseline questionnaire after the first $9 \%$ were recruited. Full details of the study design and methods are described elsewhere, and study questionnaires can be viewed at http:// www.millionwomen.org. The study was approved by the Anglia and Oxford Multi-Centre Research Ethics Committee. All participants gave their written consent to take part in the study.

At recruitment women were asked to report the number of children they had (including still births). We used this information to define parity. Women were asked to report, for each birth, if they had breastfed and if so, the duration of breastfeeding in months. We used this information to define breastfeeding (ever or never), and total duration of breastfeeding (summation over all children of reported duration of breastfeeding in months). We also calculated the average duration of breastfeeding per child using each woman's total duration of breastfeeding divided by her parity. No questions were asked about the exclusivity of breastfeeding.

${ }^{1}$ Cancer Epidemiology Unit, University of Oxford, Oxford, UK and ${ }^{2}$ National Perinatal Epidemiology Unit, University of Oxford, Oxford, UK. Correspondence: Dr KL Bobrow, Cancer Epidemiology Unit, University of Oxford, Richard Doll Building, Oxford OX3 7LF, UK.

E-mail: kirsty.bobrow@ceu.ox.ac.uk

${ }^{3}$ See Appendix.

Received 11 January 2012; revised 22 March 2012; accepted 31 March 2012; published online 10 July 2012 
Women's reported current weight and height at recruitment were used to derive $\mathrm{BMI}(\mathrm{BMI})$ as weight $(\mathrm{kg}) / \mathrm{height}(\mathrm{m})^{2}$ and this value was used in the analyses. For a random sample of 2800 women weight and height were measured by their general practitioners. We used this information to compare BMIs calculated from self-reported data to BMls calculated from measured data, using Spearman's correlation and analyses suggest by Bland and Altman. ${ }^{24,25}$

\section{Analyses}

The main outcome was BMI, treated as a continuous variable. The main exposure variables were parity and duration of breastfeeding treated as categorical variables. Parity was summarized as $0,1,2,3$ or 4 or more; and total duration of breastfeeding as never breastfed, breastfed for $<6$ months, breastfed for 6-9 months, or breastfed for 10 months or more (approximate tertiles of total duration for women who breastfed). The following potential confounders were included in statistical models for the main analyses: age (continuous variable), region of residence (10 regions in the UK), quintiles of socioeconomic status based on the Townsend deprivation index, ${ }^{26}$ smoking (never, past, current $<15$ cigarettes per day, current $\geqslant 15$ cigarettes per day) and strenuous physical activity ( $\leqslant 1$ time per week, 2-3 times per week, $\geqslant 4$ times per week).

We used linear regression to estimate the mean change in BM associated with increasing parity and duration of breastfeeding, with adjustment for all of the factors listed above. Mean BMIs, standardised by the variables listed above, were estimated using the regression coefficients in categories of parity, breastfeeding, socioeconomic group, smoking and physical activity. Where appropriate, we fitted parity and duration of breastfeeding as continuous variables in tests for trend. When results are presented as figures they show the standardised mean BMI (with 95\% confidence intervals $(\mathrm{Cls})$ ) for categories of parity, breastfeeding and, where appropriate, other factors.

A total 801155 postmenopausal women with information about their childbearing and breastfeeding histories and who had not previously been diagnosed with a cancer (other than non-melanoma skin cancer) were eligible for analysis. Women were classified as postmenopausal if they reported their periods stopped naturally or after bilateral oophorectomy, or if they were aged 53 years or older ( $88 \%$ of women aged $\geqslant 53$ years who had not had a hysterectomy or used HRT were postmenopausal by that age). The analyses were restricted to women with complete information on potential confounders. We excluded $0.7 \%$ (6358) of women with missing information on socioeconomic group, 1.4\% (13075) of women with missing information on physical activity and 4.4\% (41 094) of women with incomplete information on smoking. All analyses were performed using STATA version 10 (Stata corporation, TX, USA) and all variables were as reported at recruitment.

\section{RESULTS}

In total, 740628 postmenopausal women were eligible for analysis. Table 1 shows characteristics of study participants by parity and, among parous women, by breastfeeding history. The mean age of the women was 57.5 (s.d. 4) years and $88 \%$ reported having had at least one child, with mean parity 2.1 (s.d. 1.2.) Among parous women the mean age at first birth was 23.9 (s.d. 4) years, the mean age at last birth was 28.5 (s.d. 5) years and $70 \%$ had ever breastfed. The mean total duration of breastfeeding was 7.7 (s.d. 8.8) months in women who had breastfed and increased with increasing parity. The mean duration of breastfeeding per child was 3.1 (s.d. 3.1) months and increased slightly with increasing parity. Compared with parous women, the nulliparous tended to be of a higher socioeconomic status, and were less likely to be current smokers, and more likely to report engaging in regular physical activity. Among the parous women, high parity was associated with lower socioeconomic status, an increasing likelihood of being a current smoker, and a lower likelihood of engaging in regular physical activity. Women who had breastfed were of a higher socioeconomic status, less likely to be current smokers, and more likely to engage in regular physical activity than women who had not breastfed.

There was strong association between BMls calculated from self-reported data and BMls calculated from measured data, Spearman's correlation coefficient 0.95 (Figure 1). Analysis using the methods suggested by Bland and Altman ${ }^{25}$ indicated that the difference in BMls based on measured and self-reported data were not significantly different from zero $\left(-0.65 \mathrm{~kg} \mathrm{~m}^{-2}, 95 \% \mathrm{Cl}\right.$ : -3.10 to $1.79 \mathrm{~kg} \mathrm{~m}^{-2}$ ).

Figure 2 shows the mean BMI by parity and breastfeeding history, standardised by age, region, socioeconomic group, smoking and physical activity. Nulliparous women had a lower mean BMl than parous women. Among parous women the standardised mean BMI increased with each additional child. Within each parity group, women who had ever breastfed had significantly lower standardised mean BMls than women who had never breastfed.

Figure 3 shows the mean BMI by parity and breastfeeding history separately for women in upper, middle and lower socioeconomic tertiles (standardised by age, region, smoking and physical activity). As expected, standardised mean BMls

Table 1. Characteristics of study participants included in these analyses by parity and breastfeeding

\begin{tabular}{|c|c|c|c|c|c|c|c|c|}
\hline \multirow[t]{3}{*}{ Population characteristics } & \multicolumn{5}{|c|}{ By parity } & \multicolumn{2}{|c|}{ By breastfeeding ${ }^{a}$} & \multirow{3}{*}{$\begin{array}{l}\text { All women } \\
\mathrm{n}=740628\end{array}$} \\
\hline & Nulliparous & One & Two & Three & $\begin{array}{l}\text { Four or } \\
\text { more }\end{array}$ & $\begin{array}{l}\text { Never } \\
\text { breastfed }\end{array}$ & $\begin{array}{c}\text { Ever } \\
\text { breastfed }\end{array}$ & \\
\hline & $\mathrm{n}=89448$ & $\mathrm{n}=100639$ & $\mathrm{n}=309841$ & $\mathrm{n}=159100$ & $\mathrm{n}=80600$ & $\mathrm{n}=201688$ & $n=449492$ & \\
\hline Age in years (mean (s.d.)) & $57(5)$ & $57(5)$ & $57(4)$ & $58(4)$ & $58(4)$ & $57(4)$ & $58(4)$ & $58(4)$ \\
\hline Parity (mean (s.d.)) & 0 & $1(0)$ & $2(0)$ & $3(0)$ & $4.4(0.8)$ & $2.1(0.9)$ & $2.5(1.0)$ & $2.1(1.2)$ \\
\hline $\begin{array}{l}\text { Women who ever } \\
\text { breastfed (\%) }\end{array}$ & 0 & 52 & 68 & 76 & 80 & 0 & 100 & 70 \\
\hline \multicolumn{9}{|l|}{ Duration breastfeeding } \\
\hline $\begin{array}{l}\text { Total duration in months } \\
\text { (mean (s.d.)) }\end{array}$ & 0 & $1.9(3.5)$ & $4.3(6.2)$ & $6.8(8.7)$ & $10.5(13.9)$ & 0 & $7.7(8.8)$ & $4.7(7.8)$ \\
\hline $\begin{array}{l}\text { Duration per child in } \\
\text { months (mean (s.d.)) }\end{array}$ & 0 & $1.9(3.5)$ & $2.1(2.9)$ & $2.3(2.9)$ & $2.3(3.0)$ & 0 & $3.1(3.1)$ & $1.9(2.9)$ \\
\hline
\end{tabular}


were consistently lower in higher socioeconomic groups, for example, in nulliparous women the standardised mean BMI was $25.3 \mathrm{~kg} \mathrm{~m}^{-2}$ in the highest socioeconomic group but signifi-

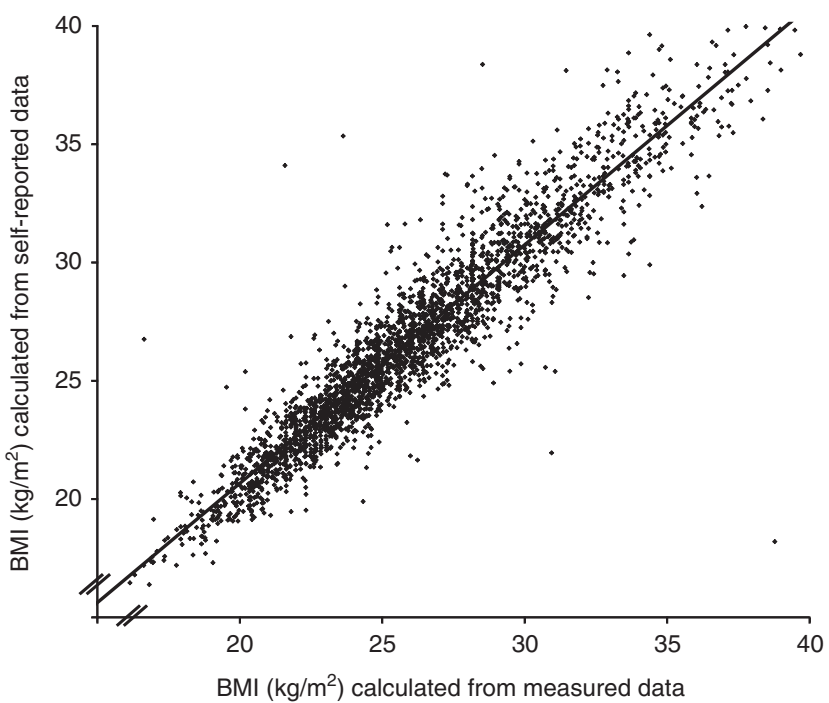

Figure 1. Scatter plot showing the association in a random sample of Million Women Study participants between BMls calculated from measured height and weight ( $x$ axis) and calculated from selfreported height and weight data from the recruitment questionnaire (y axis).

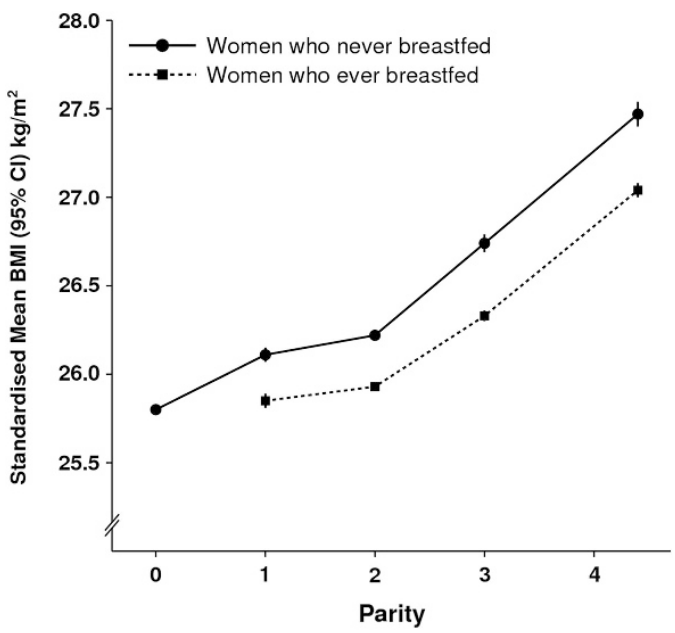

Figure 2. Mean BMI $\left(\mathrm{kg} \mathrm{m}^{-2}\right)$ by parity and breastfeeding standardized by age, region, socioeconomic group, smoking and physical activity. cantly higher $(P<0.0001)$, at $26.4 \mathrm{~kg} \mathrm{~m}^{-2}$, in the lowest group (a difference of $1.1(1.0-1.2) \mathrm{kg} \mathrm{m}^{-2}$ ) Nevertheless, within each socioeconomic group the pattern of increasing standardised mean BMI with increasing parity being offset by breastfeeding is clear (Figure 3).

Table 2 shows the estimated change in mean BMI with increasing parity (adjusted for total duration of breastfeeding) and with increasing total duration of breastfeeding (adjusted for parity). Results are shown both with standardization for age and region only and with additional adjustment by socioeconomic group, smoking and physical activity. Although standardization by these additional factors slightly attenuated the results, strong independent effects of increasing parity and increasing duration of breastfeeding on standardised mean BMI remained.

Figure 4 illustrates the effect of increasing duration of breastfeeding on the relationship between parity and standardised mean BMI. Again it can be seen that parity and breastfeeding independently affect BMI. It can also be seen that at every level of parity, the standardised mean BMI is lower the longer the average duration of breastfeeding per child.

Figure 5 shows the standardised mean BMI by parity, total duration of breastfeeding, socioeconomic group, smoking and physical activity (for each characteristic the mean BMI is standardised for all other factors shown in the figure). It can be seen that each characteristic has an independent effect on BMI in this population of postmenopausal women. Comparing the relative magnitude of the effects of each factor on standardised mean BMI, women with parity of four or more have a mean BMI $1.7 \mathrm{~kg} \mathrm{~m}^{-2}(1.6-1.7)$ greater than nulliparous women and parous women with a total duration of breastfeeding of 10 months or more (on average 18 months) have a mean BMl $0.5 \mathrm{~kg} \mathrm{~m}^{-2}$ (0.5 to 0.6) lower than women with similar characteristics who had not breastfed their children. The difference in standardised mean BMI between women in the lowest and highest socioeconomic quintiles was $1.2 \mathrm{~kg} \mathrm{~m}^{-2}(1.1-1.2)$, and between never and current smokers was $1.1 \mathrm{~kg} \mathrm{~m}^{-2}(1.0-1.1)$. Women who reported engaging in physical activity four or more times per week had standardised mean BMls $1.8 \mathrm{~kg} \mathrm{~m}^{-2}(1.7-1.8)$ lower than women who engaged in physical activity less than once per week.

\section{DISCUSSION}

In this study of almost 750000 postmenopausal middle-aged women in the UK (aged 57.5 years on average) we found persistent and important effects of their parity and breastfeeding histories on their BMI. These associations were independent of other known factors that are associated with adipositysocioeconomic group, smoking and physical activity.

As both parity and breastfeeding have independent (but opposing) effects on BMI, analyses that do not take account of both factors will tend to underestimate slightly the effect of each on women's BMI. Nevertheless, an increased BMI associated with
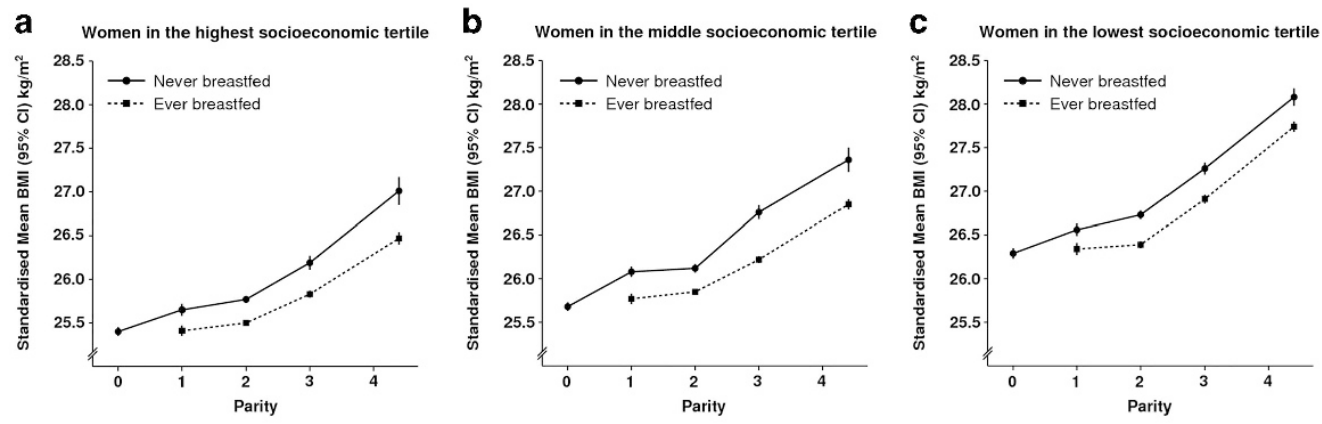

Figure 3. Mean BMI $\left(\mathrm{kg} \mathrm{m}^{-2}\right)$ by parity and breastfeeding status standardized by age, region, smoking and physical activity in upper, middle and lower socioeconomic tertiles. 


\begin{tabular}{|c|c|c|c|c|c|}
\hline & $\begin{array}{c}\text { Number } \\
\text { of } \\
\text { women }\end{array}$ & Unadjusted results & $\begin{array}{l}\text { Model } A \text {-standardised } \\
\text { by age and region only }\end{array}$ & $\begin{array}{c}\text { Model } A+\text { additionally } \\
\text { standardised by } \\
\text { breastfeeding (when } \\
\text { looking at parity), and } \\
\text { for parity (when looking } \\
\text { at breastfeeding) }\end{array}$ & $\begin{array}{c}\text { Model A + additionally } \\
\text { standardised by } \\
\text { breastfeeding, parity, } \\
\text { socioeconomic group, } \\
\text { smoking and } \\
\text { physical activity }\end{array}$ \\
\hline \multicolumn{6}{|l|}{ Parity (mean) } \\
\hline 1 & 100639 & Reference & Reference & Reference & Reference \\
\hline 2 & 310841 & $-0.02(-0.05$ to 0.01$)$ & $-0.01(-0.04$ to 0.02$)$ & $0.11(0.08$ to 0.14$)$ & $0.13(0.09$ to 0.16$)$ \\
\hline 3 & 159100 & 0.45 (0.41 to 0.48$)$ & 0.45 (0.41 to 0.48$)$ & $0.63(0.60$ to 0.67$)$ & $0.58(0.55$ to 0.62$)$ \\
\hline$\geqslant 4(4.4)$ & 80600 & $1.31(1.27$ to 1.36$)$ & $1.30(1.26$ to 1.34$)$ & 1.53 (1.49 to 1.58$)$ & $1.33(1.28$ to 1.37$)$ \\
\hline \multicolumn{6}{|c|}{ Total duration of breastfeeding (mean in months) } \\
\hline Did not breastfeed & 201688 & Reference & Reference & Reference & Reference \\
\hline$<6$ months $(2.3)$ & 239836 & $-0.27(-0.24$ to -0.30$)$ & $-0.26(-0.24$ to -0.29$)$ & $-0.32(-0.29$ to -0.35$)$ & $-0.24(-0.21$ to -0.26$)$ \\
\hline 6-9 months (7.3) & 82198 & $-0.43(-0.40$ to -0.47$)$ & $-0.42(-0.38$ to -0.46$)$ & $-0.52(-0.48$ to -0.56$)$ & $-0.36(-0.32$ to -0.40$)$ \\
\hline$\geqslant 10$ months $(18.5)$ & 127458 & $-0.44(-0.41$ to -0.48$)$ & $-0.43(-0.40$ to -0.46$)$ & $-0.75(-0.71$ to -0.78$)$ & $-0.53(-0.50$ to -0.57$)$ \\
\hline $\begin{array}{l}\text { Change in mean BMI per } \\
6 \text { months breastfeeding }\end{array}$ & & $-0.12(-0.11$ to -0.13$)$ & $-0.11(-0.10$ to 0.12$)$ & $-0.17(-0.16$ to -0.18$)$ & $-0.13(-0.11$ to -0.13$)$ \\
\hline
\end{tabular}

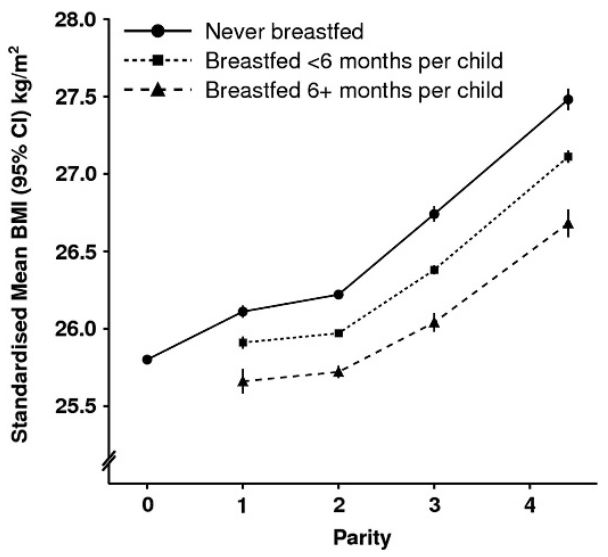

Figure 4. Mean BMI $\left(\mathrm{kg} \mathrm{m}^{-2}\right)$ by parity and increasing of breastfeeding per child standardized by age, region, socioeconomic group, smoking and physical activity.

increasing parity in middle-aged women is consistent with previous reports by some, but not all, investigators. ${ }^{11-16}$ To date only two small studies have reported on the relationship between breastfeeding history and BMI or a related measure in later life, and their findings are also broadly consistent with ours: among middle-aged Swedish women the risk of abdominal obesity decreased with their duration of breastfeeding ${ }^{17}$ and among Dutch middle-aged women (born during the 1944/46 Dutch famine, who therefore may be a somewhat atypical population), BMI was lower among women who had breastfed than among those who had not. ${ }^{18}$

The relationships between parity, breastfeeding and BMI found here are highly statistically significant and unlikely to be due to chance. They are also unlikely to be the result of reverse causation as childbearing and breastfeeding occurred on average 30 years before women's weights and heights were recorded in this study. In this study socioeconomic status, smoking and physical activity were all related to $\mathrm{BMI}$, but the observed associations with childbearing are not confounded by these factors. After adjusting for them the association between parity, breastfeeding and BMI was only slightly attenuated, and in mutually adjusted and stratified analyses the associations between BMI and parity and breastfeeding were shown to be largely independent of the other risk factors. The associations between BMI and socioeconomic group, smoking and physical activity in this study are of a broadly similar magnitude to those reported in the published literature. ${ }^{19-22}$

Parity and breastfeeding history were obtained by self-report, and long-term recall of these events is reliable. ${ }^{27-30}$ Breastfeeding frequency and duration in this cohort is consistent with published findings for women of similar birth cohorts in other European countries. $^{31}$ BMI was calculated using women's self-reported heights and weights and may be affected by random and systematic measurement error. ${ }^{32}$ This is unlikely to be a material source of bias; when comparing self-reported versus measured height and weight data we found a strong correlation between BMls calculated from measured data and BMls calculated from self-reported data (Spearman's correlation coefficient 0.95). ${ }^{33}$ We also found that the difference between mean measured and selfreported BMls was not significantly different from zero. ${ }^{3}$

Strengths of this study include its size and the availability of information about potential confounders. The Million Women Study includes about one in four UK women aged between 50 and 64 years at the time of recruitment. The study population is ethnically homogenous with $98 \%$ reporting they were white. Detailed information on socioeconomic factors, smoking and physical activity allowed for fine subdividing by these key potential confounders while retaining sufficient power to assess the effects of childbearing and breastfeeding on BMI.

Our findings and those from related publications on the association between childbearing and adiposity are from developed countries, and do not necessarily apply to women in other settings, particularly in developing countries. For women in the UK, and probably also women in other developed countries, our results provide good evidence that even after the menopause childbearing history has a persistent effect on BMI and that the magnitude of some of these effects are of a similar order of magnitude as established risk factors, such as socioeconomic group, smoking and physical activity. For example, the difference in standardised mean BMI between women with 4 or more children versus one child is similar to the difference in standardised mean BMI between women in the highest versus the lowest socioeconomic quintiles.

We found that breastfeeding was associated with a long-term reduction in BMI among postmenopausal women. Women's average BMI decreased by $0.22 \mathrm{~kg} \mathrm{~m}^{-2}$, for every 6 months that they breastfed, equivalent to about a $1 \%$ reduction in average $\mathrm{BMI}$ in the study population. Such a reduction in 


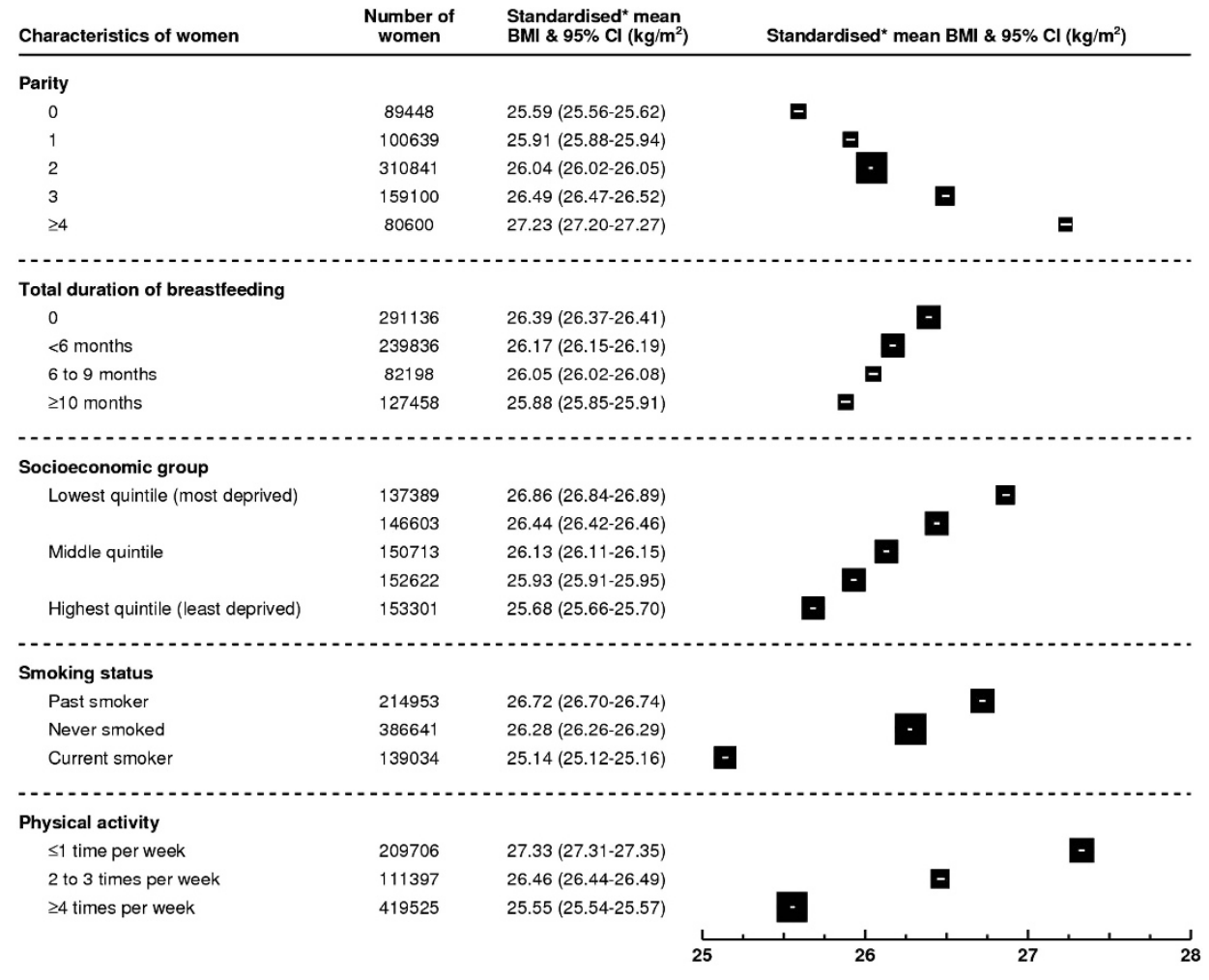

* standardised by age, region, parity, total duration of breastfeeding, socioeconomic group, smoking status and physical activity, as appropriate.

Figure 5. Standardised* mean BMI $\left(\mathrm{kg} \mathrm{m}^{-2}\right)$ among postmenopausal women by selected characteristics.

mean BMI has been associated with about a $1 \%$ decrease in all-cause mortality. ${ }^{2}$ Although these numbers seem small, 'even a modest $1 \%$ reduction in BMI would substantially reduce the number of obesity-related diseases and their costs'. During peripartum counselling on infant feeding choices, it seems relevant to inform women that breastfeeding is associated with a relatively small, but important, persistent reduction in their weight decades later.

\section{CONFLICT OF INTEREST}

The authors declare no conflict of interest.

\section{ACKNOWLEDGEMENTS}

This work was supported by Cancer Research UK and the Medical Research Council. The funders did not participate in the study design and conduct or in the collection, management, analysis and interpretation of the data, nor did they have any input into the preparation, review or approval of this manuscript. KB was in receipt of a Rhodes Scholarship. We thank the women who participated in the Million Women Study and Adrian Goodill for preparation of the figures.

\section{REFERENCES}

1 Dietz WH. Reversing the tide of obesity. Lancet 2011; 378: 744-746.

2 Whitlock G, Lewington S, Sherliker P, Clarke R, Emberson J, Halsey J et al. Bodymass index and cause-specific mortality in 900000 adults: collaborative analyses of 57 prospective studies. Lancet 2009; 373: 1083-1096.

3 Reeves GK, Pirie K, Beral V, Green J, Spencer E, Bull D et al. Cancer incidence and mortality in relation to body mass index in the Million Women Study: cohort study. BMJ 2007; 335: 1134-1145.

4 Sheldon JH. Maternal obesity. Lancet 1949; 2: 869-873.
5 Harris HE, Ellison GT, Holliday M. Is there an independent association between parity and maternal weight gain? Ann Hum Biol 1997; 24: 507-519.

6 Gunderson EP, Abrams B. Epidemiology of gestational weight gain and body weight changes after pregnancy. Epidemiol Rev 1999; 21: 261-275.

7 Ohlin A, Rossner S. Factors related to body weight changes during and after pregnancy: the Stockholm Pregnancy and Weight Development Study. Obes res 1996; 4: 271-276.

8 Sichieri $\mathrm{R}$, Field AE, Rich-Edwards J, Willett WC. Prospective assessment of exclusive breastfeeding in relation to weight change in women. Int J Obes Relat Metab Disord 2003; 27: 815-820.

9 Gunderson EP, Jacobs Jr DR, Chiang V, Lewis CE, Feng J, Quesenberry Jr CP et al. Duration of lactation and incidence of the metabolic syndrome in women of reproductive age according to gestational diabetes mellitus status: a 20-year prospective study in CARDIA (Coronary Artery Risk Development in Young Adults). Diabetes 2010; 59: 495-504.

10 Gunderson EP, Hedderson MM, Chiang V, Crites Y, Walton D, Azevedo RA et al. Lactation intensity and postpartum maternal glucose tolerance and insulin resistance in women with recent GDM: the SWIFT cohort. Diabetes Care 2012; 35: $50-56$.

11 Heliövaara M, Aromaa A. Parity and obesity. J Epidemiol Community Health 1981; 35: 197-199.

12 Kaye SA, Folsom AR, Prineas RJ, Potter JD, Gapstur SM. The association of body fat distribution with lifestyle and reproductive factors in a population study of postmenopausal women. Int J Obes 1990; 14: 583-591.

13 Bjorkelund C, Lissner L, Andersson S, Lapidus L, Bengtsson C. Reproductive history in relation to relative weight and fat distribution. Int J Obes Relat Metab Disord 1996; 20: 213-219.

14 Weng HH, Bastian LA, Taylor DH, Moser BK, Ostbye T. Number of children associated with obesity in middle-aged women and men: results from the Health and Retirement Study. J Women's Health 2004; 13: 85-91.

15 Newby PK, Dickman PW, Adami H, Wolk A. Early anthropometric measures and reproductive factors as predictors of body mass index and obesity among older women. Int J Obes Relat Metab Disord 2005; 29: 1084-1092. 
16 Bastian LA, West NA, Corcoran C, Munger RG. Number of children and the risk of obesity in older women. Prev Med 2005; 40: 99-104.

17 Ram KT, Bobby P, Hailpern SM, Lo JC, Schocken M, Skurnick J et al. Duration of lactation is associated with lower prevalence of the metabolic syndrome in midlife-SWAN, the study of women's health across the nation. Am J Obstet Gynecol 2008; 198: 268.e1-268.e6.

18 Rush D, Lumey LH, Ravelli AC, Myers B. The indirect association of lactation with subsequent perimenopausal body weight. Eur J Clin Nutr 1996; 50: 12-16.

19 Hu FB. Obesity epidemiology. Oxford University Press: New York, 2008; 514 p.

20 Wamala SP, Wolk A, Orth-Gomér K. Determinants of obesity in relation to socioeconomic status among middle-aged Swedish women. Prev Med 1997; 26: 734-744.

21 Molarius A, Seidell JC, Kuulasmaa K, Dobson AJ, Sans S. Smoking and relative body weight: an international perspective from the WHO MONICA Project. J Epidemiol Community Health 1997; 51: 252-260.

22 Tucker LA, Peterson TR. Objectively measured intensity of physical activity and adiposity in middle-aged women. Obesity 2003; 11: 1581-1587.

23 The Million Women Study Collaborative Group. The Million Women Study: design and characteristics of the study population. Breast Cancer Res 1999; 1: 73-80.

24 Kirkwood BR, Sterne JAC. Essential Medical Statistics. 2nd edn, Blackwell Science: Oxford, Wiley-Blackwell, 2003.

25 Altman DG, Bland JM. Measurement in medicine: the analysis of Method Comparison Studies. J R Stat Soc Ser D 1983; 32: 307-317.

26 Townsend P, Phillimore P, Beattie A. Health and Deprivation: ineqality in the North. London: Crom Helm, 1988.

\section{APPENDIX}

Million Women Study Steering Committee

Emily Banks, Valerie Beral, Ruth English, Jane Green, Julietta Patnick, Richard Peto, Gillian Reeves, Martin Vessey and Matthew Wallis.

The Million Women Study Co-ordinating Centre staff are as follows: Simon Abbott, Miranda Armstrong, Krys Baker, Angela Balkwill, Emily Banks, Vicky Benson, Valerie Beral, Judith Black, Kirsty Bobrow, Anna Brown, Diana Bull, Benjamin Cairns, Karen Canfell, Delphine Casabonne, James Chivenga, Barbara Crossley, Dave Ewart, Sarah Ewart, Lee Fletcher, Toral Gathani, Laura Gerrard, Adrian Goodill, Jane Green, Isobel Lingard, Elizabeth Hilton, Sau Wan Kan, Carol Keene, Oksana Kirichek, Nicky Langston, Bette Liu, Maria-Jose Luque, Lynn Pank, Kirstin Pirie, Gillian Reeves, Andrew Roddam, Emma Sherman, Evie SherryStarmer, Moya Simmonds, Elizabeth Spencer, Richard Stevens, Helena Strange, Sian Sweetland, Alison Timadjer, Sarah Tipper,
27 Buka SL, Goldstein JM, Seidman L, Tsuang MT. Maternal recall of pregnancy history: accuracy and bias in schizophrenia research. Schizophr Bull 2000; 26: 335-350.

28 Tomeo CA, Rich-Edwards JW, Michels KB, Berkey CS, Hunter DJ, Frazier AL et al. Reproducibility and validity of maternal recall of pregnancy-related events. Epidemiology 1999; 10: 774-777

29 Promislow JHE, Gladen BC, Sandler DP. Maternal recall of breastfeeding duration by elderly women. Am J Epidemiol 2005; 161: 289-296.

30 Collaborative Group on Hormonal Factors in Breast Cancer. Breast cancer and breastfeeding: collaborative reanalysis of individual data from 47 epidemiological studies in 30 countries, including 50302 women with breast cancer and 96973 women without the disease. Lancet 2002; 360: 187-195.

31 Ko KP, Park SK, Kim Y, Bae J, Jun JK, Gwack J et al. Reliability of a questionnaire for women's reproductive history. J Prev Med Public Health 2008; 41: 181-185.

32 Whitlock G, Clark T, Hoorn SV, Rodgers A, Jackson R, Norton R et al. Random errors in the measurement of 10 cardiovascular risk factors. Eur J Epidemiol 2001; 17: 907-909.

33 Spencer EA, Roddam AW, Key TJ. Accuracy of self-reported waist and hip measurements in 4492 EPIC-Oxford participants. Public Health Nutr 2004; 7: 723-727.

(c) This work is licensed under the Creative Commons AttributionNonCommercial-No Derivative Works 3.0 Unported License. To view a copy of this license, visit http://creativecommons.org/licenses/by-nc-nd/3.0/

Joanna Watson, Lucy Wright, Heather Young. Collaborating UK NHS breast screening centres: Avon, Aylesbury, Barnsley, Basingstoke, Bedfordshire and Hertfordshire, Cambridge and Huntingdon, Chelmsford and Colchester, Chester, Cornwall, Crewe, Cumbria, Doncaster, Dorset, East Berkshire, East Cheshire, East Devon, East of Scotland, East Suffolk, East Sussex, Gateshead, Gloucestershire, Great Yarmouth, Hereford and Worcester, Kent, Kings Lynn, Leicestershire, Liverpool, Manchester, Milton Keynes, Newcastle, North Birmingham, North East Scotland, North Lancashire, North Middlesex, North Nottingham, North of Scotland, North Tees, North Yorkshire, Nottingham, Oxford, Portsmouth, Rotherham, Sheffield, Shropshire, Somerset, South Birmingham, South East Scotland, South East Staffordshire, South Derbyshire, South Essex, South Lancashire, South West Scotland, Surrey, Warrington Halton St Helens and Knowsley, Warwickshire Solihull and Coventry, West Berkshire, West Devon, West London, West Suffolk, West Sussex, Wiltshire, Winchester, Wirral and Wycombe. 